\title{
Comparison of low back fusion techniques: transforaminal lumbar interbody fusion (TLIF) or posterior lumbar interbody fusion (PLIF) approaches
}

\author{
Chad D. Cole · Todd D. McCall • Meic H. Schmidt • \\ Andrew T. Dailey
}

Published online: 29 April 2009

(C) The Author(s) 2009. This article is published with open access at Springerlink.com

\begin{abstract}
The authors review and compare posterior lumbar interbody fusion (PLIF) with transforaminal lumbar interbody fusion (TLIF). A review of the literature is performed wherein the history, indications for surgery, surgical procedures with their respective biomechanical advantages, potential complications, and grafting substances are presented. Along with the technical advancements and improvements in grafting substances, the indications and use of PLIF and TLIF have increased. The rate of arthrodesis has been shown to increase given placement of bone graft along the weight-bearing axis. The fusion rate across the disc space is further enhanced with the placement of posterior pedicle screw-rod constructs and the application of an osteoinductive material. The chief advantages of the TLIF procedure compared with the PLIF procedure included a decrease in potential neurological injury, improvement in lordotic alignment given graft placement within the anterior column, and preservation of posterior column integrity through minimizing lamina, facet, and pars dissection.
\end{abstract}

Keywords Posterior lumbar interbody fusion .

Transforaminal lumbar interbody fusion .

Degenerative disc disease - Low back pain · History ·

Fusion - Complications

C. D. Cole · T. D. McCall · M. H. Schmidt · A. T. Dailey ( $ه)$ Department of Neurosurgery, University of Utah Medical Center, 175 N. Medical Drive East, Salt Lake City, UT 84132, USA

e-mail: andrew.dailey@hsc.utah.edu

\section{Introduction}

Lumbar spinal fusion was introduced approximately 70 years ago and has evolved as a treatment option for symptomatic spinal instability, spinal stenosis, spondylolisthesis, and degenerative scoliosis [1]. Broader applications including use as a treatment of chronic low back pain and recurrent radiculopathy have resulted in a dramatic increase in the rates of lumbar fusion procedures within the last decade in the United States [1, 2]. Lumbar spinal fusion is often performed after a posterior decompressive procedure when there is evidence of preoperative lumbar spinal deformity or instability that could worsen after laminectomy alone [3].

Along its evolutionary trail, various methods for achieving circumferential fusion have arisen. Distinct from staged anterior/posterior fusion techniques, two methods of achieving an interbody fusion from a posterior approach have emerged: posterior lumbar interbody fusion (PLIF) and transforaminal lumbar interbody fusion (TLIF). The aims of this review are to examine the history of PLIF and TLIF, understand their indications and the surgical methodology, as well as compare and contrast their biomechanical advantages, potential complications, and clinical outcomes.

\section{History}

The PLIF procedure was first described in 1944 by Briggs and Milligan [4], who used laminectomy bone chips in the disc space as interbody graft. In 1946, Jaslow [5] modified the technique by positioning an excised portion of the spinous process within the intervertebral space. It was not until 1953 when Cloward [6] described his technique, which used 
impacted blocks of iliac crest autograft that the popularity of PLIF surgery increased. Although technically more difficult than posterolateral fusion techniques (i.e., intertransverse fusion in which bone graft spans between the transverse processes), the PLIF procedure was found to have the advantage of substantially increased fusion rates, often in excess of $85 \%$. Despite the increased fusion rate, this technique was fraught with complications related to blood loss, dural/neural injury, graft extrusion, and arachnoiditis.

Because of the technical challenges, the use of the PLIF procedure remained significantly limited until the 1990s, at which time the advent of preformed supplementary interbody implants and instruments with which to insert them increased the technical ease and subsequent popularity of this technique [7-15]. Structural implants, such as synthetic cages or premilled allograft, have now become a standard part of PLIF to support and stabilize the disc space until bone graft unites the bone of the opposing vertebral endplates [16, 17].

The use of rigid interbody instrumentation to promote fusion was originally reported by Wagner et al. [18, 19], who fashioned a cage and bone implant to effect cervical spine fusions in horses with "wobblers syndrome" [12]. Using a slightly oversized, extensively perforated, stainless steel cylinder (the "Bagby Basket") that could be filled with local autogenous bone graft, the intervertebral disc space could be restored, and an $88 \%$ fusion rate was achieved [20]. Butts et al. [21] further developed the Bagby concept by biomechanically testing the use of two parallel implants interposed between the lumbar vertebral bodies. With distraction, the implant was placed so that compression of the implant against the subchondral bone produced immediate stability [21]. Using the "Bagby Basket" as a foundation, further development in materials and physical characteristics resulted in the production of what is known today as the Bagby and Kuslich (BAK) cage [22].

With newer implants and standard sets of instruments, fusion rates of the PLIF procedure have improved, with some authors reporting successful fusion in more than $90 \%$ of patients [17]. The popularity of this technique has continued to increase. Many authors have subsequently proposed using a variety of graft types, including autologous iliac crest bone graft, shaped allograft dowels or wedges, and bone chips [12, 23-26]. More recently, interbody cages have become popular and are now composed of a wide range of materials, such as titanium mesh, carbon fiber, and polyether ether ketone (PEEK) [16]. Not only have fusion rates improved with this evolution, but technological advances in these implants have also improved their safety and ease of application, further adding to the popularity of the PLIF procedure. Finally, augmentation of the PLIF procedure with the addition of pedicle screws increases the stability of the construct and has been reported to increase the fusion rate of this procedure compared with stand-alone grafts [14, 27].

Posterior lumbar interbody fusion requires retraction of the thecal sac and nerve roots to gain sufficient access to the posterior disc space through the spinal canal. This increases the risks of incidental durotomy and injury to the nerve roots or conus medullaris if above L2-3. Rates of neural injury increase when the PLIF procedure is used as a revision surgery because of the epidural scar tissue formation. The use of threaded dowels and cages for PLIF has been associated with postoperative radiculopathy in up to $13 \%$ of cases [28]. At times, PLIF requires violation of the structural integrity of both facet joints to achieve adequate graft placement, which may increase the immediate postoperative instability and lead to failure if pedicle screw instrumentation is not added [29].

In 1982, Harms and Rolinger [30] reported use of bone graft packed in a titanium mesh that was inserted via a transforaminal route into the disc space. Termed "transforaminal lumbar interbody fusion" (TLIF), their technique relied on distracting the motion segment through pedicle screws that were placed before cage insertion, and it could be accomplished without exposing more than the ipsilateral foramen. By removing the entire facet joint, it minimizes retraction on the thecal sac, decreasing the risk for a durotomy and limiting possible neurological injury [30]. TLIF enables placement of the graft within the anterior or middle of the disc space to restore lumbar lordosis. Finally, because the contralateral laminae and spinous processes can be preserved, additional surface area is available to help achieve a posterior fusion.

\section{Indications}

The advent of interbody devices and posterior screw-rod fixation has lowered the rate of pseudarthrosis associated with the PLIF and TLIF procedures; consequently, the indications for these surgical procedures have broadened.

The principal indication for lumbar interbody fusion surgery is the stabilization and fusion of adult spinal deformity. Therefore, lumbar fusion has been described as a treatment of symptomatic spondylolisthesis, degenerative scoliosis, and spinal stenosis associated with instability [6, 8, 12, 31]. For those with lumbar stenosis but without spondylolisthesis (deformity), the surgical management has traditionally involved posterior decompressive procedures, including laminectomy or laminotomy, and judicious use of partial medial facetectomies and foraminotomies, with or without discectomy $[32,33]$. In patients with evidence of spinal instability, however, in situ posterior lumbar fusion is recommended as a treatment option in addition to decompression in the setting of lumbar stenosis [32]. 
Secondary indications include recurrent lumbar disc herniation, where extensive bony removal is necessary for exposure of the disc fragments, lateral or massive disc herniations, failed previous lumbar fusions by other techniques, and discogenic low back pain [31]. Because the cause of spinal pain is not completely understood and remains controversial, surgical efforts to treat such conditions also remain controversial [34]. The description of spinal pain is often referred to as "lumbar segmental instability" [35, 36] caused by degenerative disc disease [37], or facet joint syndrome [35, 38] when no signs of increased motion or spondylolisthesis exist [39]. It is likely that biochemical mediators also play a role, but it is highly unlikely that these factors, in and of themselves, generate the spinal tissue pathology [40, 41]. In addition, the expression of symptoms may be clouded by sociologic factors and personal psychodynamics [42]. Although most cases of low back pain are transient and relieved by comfort measures along with temporary activity modification, conservative management remains ineffective in approximately $5 \%$ of cases that go on to become chronic and disabling [43, 44], resulting in a need for more aggressive treatment.

Typically, patients with a symptomatic herniated disc refractory to medical management undergo discectomy without fusion. For those undergoing primary lumbar disc excision, there is no convincing evidence to support the routine use of lumbar fusion [1]. Lumbar spinal fusion may be used as a potential adjunct, however, in patients with a herniated disc in whom there is evidence of preoperative spinal deformity [1]. Because lumbar deformity, instability, or even chronic low back pain may occur as a result of a reoperative lumbar discectomy, fusion is often considered in the setting of repeated lumbar disc herniations [1].

\section{PLIF: surgical technique}

Patients are placed prone on a surgical frame (i.e., Jackson table) to accentuate a lordotic position of the lumbar spine. After the levels of interest are exposed, the posterior spinal elements are removed to expose the traversing nerve roots and lateral extent of the disc space (Figs. 1,2). The dorsal third of the interspinous ligament may be preserved to act as a fulcrum for a dural retractor and to preserve a tension band posteriorly. The thecal sac and traversing nerve roots are mobilized and retracted to the midline, with care taken to protect the dural and neural contents with a retractor. After exposure of the posterior annulus, a complete discectomy is performed using rongeurs, disc shavers, and downbiting curved curettes. Only by completely removing the disc and denuding the cartilaginous endplates can an environment conducive to fusion be provided. In addition,

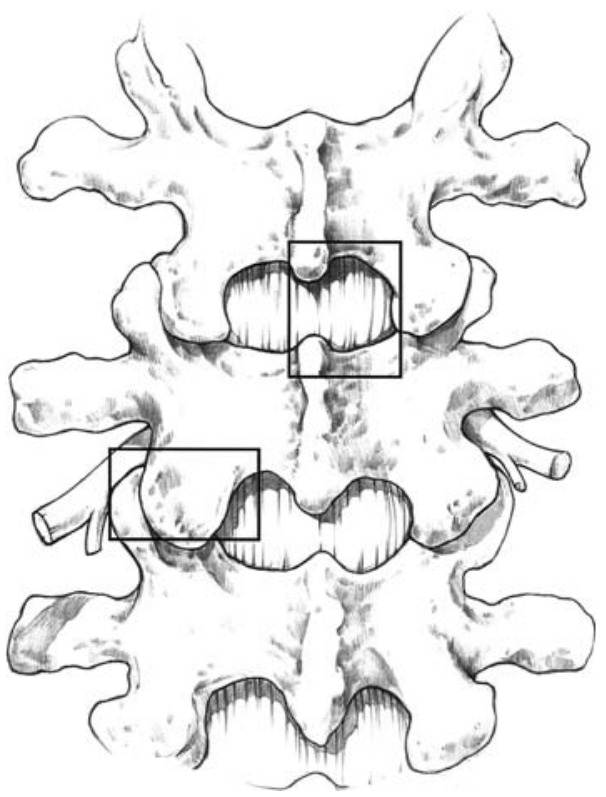

Fig. 1 Schematic representation of lumbar spine demonstrating the area of bony removal and route of access to the intervertebral body space. (Top) Medial box represents area and access for the PLIF procedure; (bottom) lateral box represents area and access for the TLIF procedure

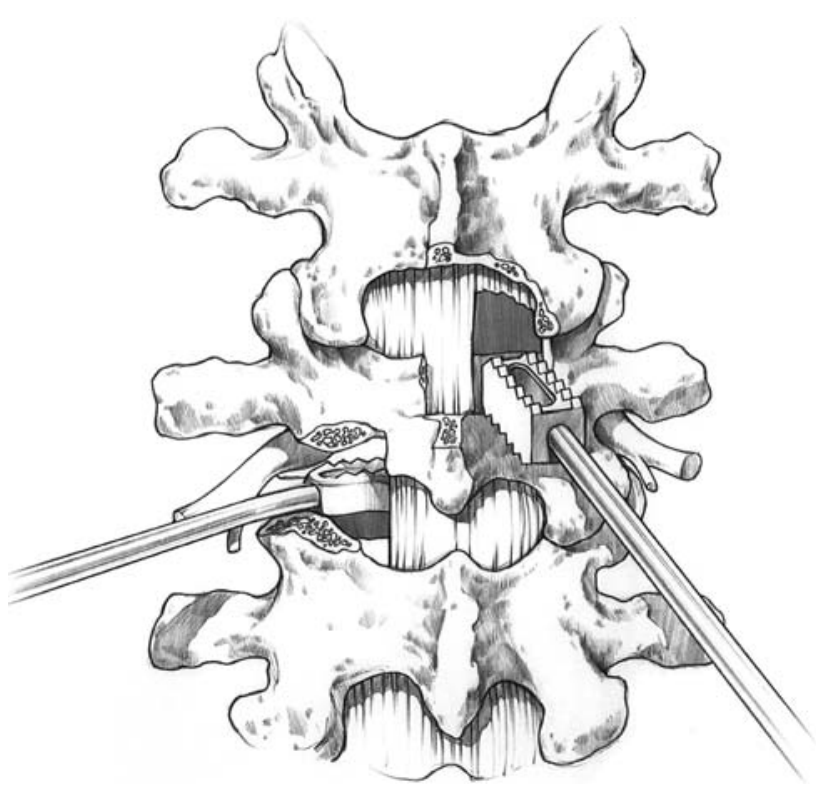

Fig. 2 Schematic representation of lumbar spine demonstrating the angle of interbody graft insertion for the PLIF procedure (top, medial) and TLIF procedure (bottom, lateral)

disc height may be restored through the use of distractors with serially increasing heights. By increasing the disc height, tension is placed on the annulus fibrosis, and the bone graft is placed under a compressive load, which will help the fusion process. 
In the case of cylindrical cages, specialized tube retractors are used to introduce serial reamers into the disc space, and this is followed by a bone tap to allow recessing of the cage. With rectangular ramp-type cages, a square channel is prepared in the disc space to accept the cage, which is then tamped into place to engage the vertebral endplates. Cage devices are filled with materials that are osteoinductive or osteoconductive and provide scaffolding for bony fusion to occur from endplate to endplate.

When placing interbody fusion devices, care must be taken to preserve the vertebral endplates upon which the devices will rest and gain their stability. The so-called "insert-and-rotate" technique for graft implants is similar to the impacted wedge technique but does not require the same amount of distraction or involve the cutting of any channel through the posterior endplates. Using interbody devices that have more contact with adjacent endplates provides more immediate stability to the construct. Implants may be made quite lordotic, especially at the L5$\mathrm{S} 1$ segment. After the interbody construct is placed, pedicle screws are then inserted and attached to the rods. Once in place, the pedicle screws are compressed along a lordotic rod in an attempt to reduce any kyphosis caused by interdiscal distraction. The transverse processes are then decorticated, and the bone graft is placed over them for a posterolateral fusion. A standard closure in layers is then performed.

Although the traditional posterior lumbar fusion has demonstrated acceptable rates of fusion, it requires an extensive incision to retract the posterior muscles and expose the transverse processes adequately. By achieving interbody fusion, a PLIF may be performed without the need for a posterolateral fusion, thereby reducing the amount of muscle retraction without sacrificing the goals of the traditional procedure [45]. By reducing retraction, immediate postoperative pain control has been easier to achieve, along with a reduced hospital length of stay compared with historical controls; however, this has not been rigorously tested.

\section{TLIF: surgical technique}

As with PLIF, patients are usually placed prone on a surgical frame (i.e., Jackson table) to facilitate a lordotic position of the lumbar spine. The surgeon begins by making a vertical incision over the section to be fused. The skin, muscles, and soft tissues are gently retracted to expose the lateral aspect of the spinous process, the lamina, and the facet joint (Figs. 1, 2). Depending on the clinical presentation, a laminectomy, facetectomy, or both may be performed. A unilateral laminotomy and partial facetectomy are performed on the side consistent with the patient's symptoms or anatomical abnormalities [46]. Depending on the need for medial exposure, a medial facetectomy is usually sufficient for exposure, although in those cases not requiring a medial decompression, exposure may be obtained by removing the lateral aspect of the inferior articular facet until the edge of the thecal sac comes into view [46]. A bilateral laminectomy is reserved for clinically significant bilateral neural element compression [46].

After adequate decompression of the neural elements has been performed, pedicle screws are placed in the standard fashion. The disc space can be gradually distracted by using the pedicle screws or an intralaminar spreading device. The placement of the distractor and screws does not interfere with the dissection and, in fact, this system allowed for easy visualization of the nerve roots, thecal sac, and disc space [46]. To facilitate complete removal of the cartilaginous endplate and a more extensive disc excision, the posterior lip of each endplate is removed with the use of a 1/4-inch osteotome, while carefully protecting the thecal sac and nerve roots [46].

An interbody device(s) of appropriate size is then placed while protecting the dura with a small retractor [46]. The thecal sac may be minimally retracted (when necessary, the retractor is used to protect the exiting nerve root) while the mesh construct is put in place [46]. Originally, the technique was described using two titanium mesh cylinders. However, single "banana"-shaped or rectangular devices have been designed to cover the disc space with a single device.

Once the graft has been placed within the interbody space, pedicle screws are then attached to lordotic rod and carefully compressed to restore lumbar lordosis while maintaining the restored disc height [46]. The contralateral facet joint may be decorticated, and the bone graft is placed over them for a posterolateral fusion if there is any instability. A standard closure in layers is performed.

Over the past few years, the TLIF approach has been augmented by use of the microscope and tubular retractor systems to make the procedure minimally invasive. The advantages include a small skin incision, decreased muscular dissection, and less retraction of the thecal sac, limiting potential of nerve root injury. There is, however, a steep learning curve and limited visual field.

\section{Biomechanical advantages and complications}

Since Cloward's [6] original description, numerous modifications of the PLIF and subsequent TLIF techniques have been reported to improve the surgical ease along with the arthrodesis rates [47-49]. These circumferential fusion techniques have some distinct theoretical advantages over 
other posterolateral techniques. First, the PLIF and TLIF procedures are more biomechanically sound because with each technique the bone graft is placed along the weightbearing axis of the spine. The graft is therefore under maximal compression with both the anterior and posterior columns under tension. Because grafts are placed near the center of rotation for a spinal motion segment, this results in greater stability with the goal of treating those problems that are discogenic in origin more directly $[6,7,12]$.

Over the past decade, the use of posterior pedicle screwrod construction has been advocated to decrease pseudarthrosis rates associated with the interbody graft placement especially when considering multilevel treatment [31, 5052]. To understand the lumbar spinal stability of a singlelevel and two-level PLIF or TLIF with or without posterior fixation, Ames et al. [53] performed a series of experiments using a model that applied a nondestructive, nonconstraining pure moment load to the lumbar spine. Loads were applied about the appropriate anatomic axes to induce six different motions: flexion, extension, right axial rotation, left axial rotation, right lateral bending, and left lateral bending. Calculations for three-dimensional displacements were made using the principles of stereophotogrammetry [53]. The researchers found no significant difference in flexibility across grafted levels for any motion (flexionextension, lateral bending, or axial rotation) when comparing an intact specimen with a single-level PLIF or TLIF [53]. The addition of pedicle screws after single-level interbody graft placement did, however, increase rigidity and subsequently decreased graft dislodgement and/or loosening especially for the PLIF construct [53]. This modest improvement of stability for a single-level fusion was found to be drastically enhanced for a two-level fusion with the likely clinical correlation a lower pseudoarthrosis rate. Ames et al. [53] found that after a two-level instrumentation, the TLIF with anterior graft placement had a higher stabilizing effect on flexion-extension movement across the operated level than the PLIF did. The most likely cause of the functional instability of the PLIF procedure when performed over two levels is the more extensive facet and disc removal [53]. In addition, the PLIF procedure limits the placement of the grafts into the anterior portion of the intervertebral disc space $[54,55]$. This may not result in a significant difference in flexibility after single-level instrumentation; however, violation of the bilateral facet joints and anterior disc spaces across two levels after the PLIF technique seems to necessitate additional posterior column support to maintain sagittal plane balance [53].

An increased arthrodesis rate over historical controls is facilitated by a wider area of intervertebral bone-to-graft contact. The interbody space has more vascularity than the posterolateral space, also increasing the potential for a solid fusion mass to form [31]. This improves blood supply to the graft from the rich cancellous portion of the vertebral centrum [45]. Furthermore, interbody fusion helps to restore disc space height, lumbar lordosis, and coronal and sagittal balance of the spine [31]. In addition, Wolff's law indicates that fusion potential is enhanced if grafts are placed under compression [31]. Interbody fusion places the bone graft in the load-bearing position, with the biomechanical stability maintained by the annulus, facet, and posterior spinous ligaments, which act as tension bands [56]. In the absence of these posterior elements, segmental fusion by means of internal fixation may act as the posterior tension band [57].

These procedures allow complete decompression of the neural foramen and nerve roots, restoration of intervertebral height, and near-total discectomy and restoration of segmental lordosis at the fused level [57]. The corresponding results for treatment of degenerative disc disease, spinal stenosis, spondylolisthesis, and segmental instability have been good, achieving 74-94\% fusion rates and clinical outcomes reported as good to excellent in $75-90 \%$ of cases [7, 8, 12, 23, 24, 26].

The potential complications of these procedures, particularly for the PLIF procedure, include the risk of nerve root injury during retraction, which may cause endoneural fibrosis and chronic radiculopathy. With an extensive posterior decompression, there is a risk of instability and subsequent pseudarthrosis. Furthermore, there is a real risk of posterior extrusion of the graft that may cause neural damage [58, 59].

In contrast, the anterior retroperitoneal or transperitoneal approach to the lumbosacral junction may be used for the same indications as the PLIF and TLIF procedures. The advantage of the ALIF (anterior lumbar interbody fusion) technique is that area from L4 to the sacrum can be readily exposed, with the best exposure of L5-S1 intervertebral space. Exposure of the L4-L5 interspace, however, may be limited because of the position of the aorta and vena cava over the ventral surface of the disc. A more complete discectomy may be accomplished anteriorly, which allows for placement of a larger graft compared with the PLIF/TLIF procedures. However, this approach has potential for complications, including vascular and bowel injuries along with superior hypogastric plexus injury and subsequent retrograde ejaculation. Furthermore, a multilevel ALIF procedure usually necessitates an accompanying posterior instrumentation to achieve immediate stability [60].

When comparing the above techniques, at present there are still no well-designed, prospective, randomized, controlled clinical trials providing Class I data establishing the superiority of one technique over another. Although interbody fusion techniques have increased fusion rates, there is limited evidence that improved fusion rates 
correlated with improved clinical outcome and reduced disability [61].

\section{Grafts}

The aim of interbody device development has been to create the best possible environment for successful arthrodesis while correcting the existing mechanical deformation with limited associated morbidity [62]. Over the past 50 years, numerous interbody grafts have been developed with design characteristics that not only restore disc height but also create lordosis through the segment, maintain sagittal balance through the segment, distract the neuroforaminal space, and restores anatomical weight bearing within the anterior column [31, 62]. In addition to the mechanical characteristics of the interspace graft, the device must also incorporate osteoconductive properties that promote fusion across the space [31]. Such devices include but are not limited to local autograft, iliac crest autograft, or cortical and cancellous allograft bone; threaded cylindrical cages made of titanium; rectangular or trapezoidal cages made of titanium, carbon fiber reinforced, or plain PEEK polymers, and bioabsorbable polymers (i.e., polylactic acids) [62-66].

The safety and efficacy of iliac crest has been demonstrated over several years by various authors $[30,54,67,68]$. While iliac crest autograft is an excellent material to promote interbody fusion, it is associated with harvest site morbidity in up to $25 \%$ of patients $[69,70]$. This led to the once exclusive use of tricortical bone allografts as interbody grafts for circumferential fusion [16]. These often developed mechanical failure, however, because they were unable to provide sufficient structural support. Because of the mechanical failure associated with the use of tricortical bone allografts, an open box design was developed using metal, carbon fiber, or PEEK for circumferential fusion [16].

Historically, most TLIFs involved placement of titanium cages in the interbody space; however, the modulus of elasticity of titanium is much greater than that of bone, and the titanium cage may subside through the vertebral body endplates (especially in patients with osteoporosis) [31]. Another disadvantage with the use of metal in cage devices is that they prevent adequate radiographic demonstration of fusion. The metal cages are opaque and cause significant scatter on computed tomography and magnetic resonance imaging. Most clinical studies have relied on dynamic radiographs to determine fusion; however, the lack of motion on flexion-extension views may only suggest the absence of gross instability [62].

Of the synthetic interbody grafts, the modulus of elasticity of bone is most closely approximated by nonresorbable polymers such as carbon fiber or PEEK, which have an unlimited supply and no risk of viral disease transmission or recipient rejection [31]. In the development of carbon fiber interbody grafts, the problem historically known to orthopedic surgeons (in total knee arthroplasties/ligament reconstructions) was the release of carbon fibers, causing inflammation of joints, synovitis, lymphatic spread, and eventual spread to central filter organs [62]. In an effort to reduce free fiber release, these fibers have been embedded in composite materials such as PEEK.

An additional advantage and the main driving force behind the use of these synthetic devices is the Young's modulus of carbon fiber composites that nearly match that of cortical bone [62]. This allows for true load sharing and less stress shielding between bone and device, leading to more rapid and higher fusion rates [62]. Another advantage of carbon fiber composites compared with metals is the improved ability to assess fusion radiographically. On the other hand, the biomechanical problem with carbon fiber has been brittleness with resultant breakage and composite materials failure [62]. In addition, the degree of micromotion has been found to be greater between carbon fiber composite and the bone interface than between either titanium alloy or stainless steel and bone [62].

With the initial use of carbon fiber and PEEK cages, collapse, slippage, and graft migration occurred in 3-10\% of cases in large case series [8]. As a possible solution, these grafts are now either threaded or ridged to help circumvent such migration [62].

Bioabsorbable polymers such as poly(1-lactide-co-d,1lactide) (PLDLA) also have a modulus of elasticity similar to bone [31]. They can be packed with autograft, and once fusion occurs the polymer is designed to resorb, leaving behind only the fused interbody bone. Like PEEK, PLDLA has an unlimited supply and does not risk transmission of viral infection or recipient rejection [68, 71]. However, bioresorbable polymer cages also have their disadvantages. They maintain their strength for a minimum period of time before they degrade. If degradation occurs without intervertebral body bone formation and fusion, instability will likely occur.

Despite a large volume of data regarding the use of synthetic bone graft substitutes or extenders, there are very few data regarding the use of osteoinductive substances to enhance bony fusion. Bone graft substitutes and extenders may be classified into two main categories, the first consisting of biological agents that induce the formation of bone from native tissues with recombinant human bone morphogenetic protein-2 (rh-BMP-2) as the best known member [72]. A second class of bone substitutes comprises calcium phosphate salts of varying composition that may be used to provide a scaffolding for new bone growth [72]. Members of this second category include $\beta$-tricalcium phosphate, hydroxyapatite, and wollanosite [72]. 
Recombinant rhBMP-2 is the best studied of all of the biological osteoinductive agents. Two clinical series have described the use of this substance in humans undergoing fusion for lumbar degenerative disease. Burkus et al. [73] investigated the use of rhBMP-2 as a substitute for autograft when used in combination with a titanium cage for anterior lumbar interbody fusion. Although there was not a statistically higher fusion rate in the rhBMP-2 group, there was an advantage in the use of rhBMP-2 in terms of a slightly shorter operating time and decreased blood loss [73]. Additionally, Boden et al. [74] examined the role of rhBMP- 2 in combination with $\beta$-tricalcium phosphate and hydroxyapatite as a bone graft substitute for posterior lumbar fusion. These authors reported fusion rates of $100 \%$ in groups treated with rhBMP- 2 compared with $40 \%$ in the autograft group [74]. Currently, rhBMP-2 is approved by the U.S. Food and Drug Administration for anterior lumbar interbody fusion using cylindrical titanium cages but not for posterior interbody spinal fusion.

Other biological bone growth stimulators have been used for the treatment of lumbar degenerative disease in humans. Kasai et al. [75] reported the use of processed calcium phosphates salts as bone graft extenders in the setting of lumbar fusion. These authors described their experience using a mixture of local autograft bone combined with varying amounts of apatite and wollanositecontaining glass ceramic [75]. Although no control group (autograft bone) was used in this report, the fusion rate between these two bone graft extenders was found to be nearly equivalent (82-83\%) [75].

The use of $\beta$-tricalcium phosphate as a bone graft extender has been reported by Linovitz and Peppers [76]. In this study, patients underwent interbody fusion procedures that involved placement of allograft bone as a structural graft and $\beta$-tricalcium phosphate as an osteoconductive matrix [76]. In all seven of their reported patients, fusion was achieved at all operated levels [76].

Finally, the use of hydroxyapatite has been reported by Thalgott et al. [77]. These authors performed retrospective analysis comparing patients treated with combination of hydroxyapatite and demineralized bone matrix. Interestingly, those treated with the combination of hydroxyapatite and demineralized bone matrix had a slightly lower fusion rate than those treated with hydroxyapatite alone. The authors, however, found comparable fusion rates with historical controls [76].

\section{Conclusion}

Since their inception 70 years ago, lumbar interbody fusion techniques have evolved into highly effective procedures, with clinical success rates near $75 \%$ and fusion rates reportedly around $90 \%$ for single-level instrumented procedures. The primary indication for the use of interbody fusion is spinal deformity or instability. Emerging secondary indications such as discogenic pain remain controversial as the understanding behind the cause of spinal pain remains vague. The advantages of the PLIF and TLIF techniques are decompression of the neural elements along with placement of a graft along the weight-bearing axis. Segmental fixation can provide immediate postoperative stability, correct anatomical deformities, and possibly enhance fusion rates, especially if multiple levels are to be fused. The advantage of the TLIF procedure is mainly to limit the possibility of dural or nerve injuries. Secondarily, the additional advantage of sparing the lamina, facet, and pars on the contralateral side provides increased surface area for fusion. The advantages of the PLIF procedure are mainly posterior decompression and the option of segmental fixation. Graft techniques, which are designed to promote osteoinduction and osteoconduction while restoring disc height and improving sagittal alignment, are continuing to evolve.

Acknowledgments We thank Kristin Kraus, M.Sc., for editorial assistance in preparing this paper.

Open Access This article is distributed under the terms of the Creative Commons Attribution Noncommercial License which permits any noncommercial use, distribution, and reproduction in any medium, provided the original author(s) and source are credited.

\section{References}

1. Resnick DK, Choudhri TF, Dailey AT, et al. Guidelines for the performance of fusion procedures for degenerative disease of the lumbar spine. Part 8: lumbar fusion for disc herniation and radiculopathy. J Neurosurg Spine. 2005;2:673-8.

2. Davis H. Increasing rates of cervical and lumbar spine surgery in the United States, 1979-1990. Spine. 1994;19:1117-23 (discussion 23-4).

3. Resnick DK, Choudhri TF, Dailey AT, et al. Guidelines for the performance of fusion procedures for degenerative disease of the lumbar spine. Part 1: introduction and methodology. J Neurosurg Spine. 2005;2:637-8.

4. Briggs $H$, Milligan P. Chip fusion of the low back following exploration of the spinal canal. J Bone Joint Surg. 1944;26:125-30.

5. Jaslow I. Intracorporeal bone graft in spinal fusion after disc removal. Surg Gynecol Obstet. 1946;82:215-22.

6. Cloward RB. The treatment of ruptured lumbar intervertebral discs by vertebral body fusion. I. Indications, operative technique, after care. J Neurosurg. 1953;10:154-68.

7. Cloward RB. Posterior lumbar interbody fusion updated. Clin Orthop Relat Res. 1985;193:16-9.

8. Collis JS. Total disc replacement: a modified posterior lumbar interbody fusion. Report of 750 cases. Clin Orthop Relat Res. 1985;193:64-7.

9. Fraser RD. Interbody, posterior, and combined lumbar fusions. Spine. 1995;20:167S-77S. 
10. Hutter CG. Posterior intervertebral body fusion. A 25-year study. Clin Orthop Relat Res. 1983;179:86-96.

11. Lee CK, Vessa P, Lee JK. Chronic disabling low back pain syndrome caused by internal disc derangements. The results of disc excision and posterior lumbar interbody fusion. Spine. 1995; 20:356-61.

12. Lin PM. Posterior lumbar interbody fusion technique: complications and pitfalls. Clin Orthop Relat Res. 1985;193:90-102.

13. Prolo DJ, Oklund SA, Butcher M. Toward uniformity in evaluating results of lumbar spine operations. A paradigm applied to posterior lumbar interbody fusions. Spine. 1986;11:601-6.

14. Steffee AD, Sitkowski DJ. Posterior lumbar interbody fusion and plates. Clin Orthop Relat Res. 1988;227:99-102.

15. Turner JA, Ersek M, Herron L, et al. Patient outcomes after lumbar spinal fusions. JAMA. 1992;268:907-11.

16. Brantigan JW, Steffee AD, Geiger JM. A carbon fiber implant to aid interbody lumbar fusion. Mechanical testing. Spine. 1991; 16:S277-82.

17. Ray CD. Threaded titanium cages for lumbar interbody fusions. Spine. 1997;22:667-79 (discussion 79-80).

18. DeBowes RM, Grant BD, Bagby GW, et al. Cervical vertebral interbody fusion in the horse: a comparative study of bovine xenografts and autografts supported by stainless steel baskets. Am J Vet Res. 1984;45:191-9.

19. Wagner P, Grant B, Bagby G. Evaluation of cervical spinal fusion as a treatment in the equine "wobbler" syndrome. Vet Surg. 1979;8:84-9.

20. Bagby GW. Arthrodesis by the distraction-compression method using a stainless steel implant. Orthopedics. 1988;11:931-4.

21. Butts M, Kuslick S, Bechtold J. Biomechanical analysis of a new method for spinal interbody fusion. Boston, MA: American Society of Mechanical Engineers; 1987.

22. Bagby G. The Bagby and Kuslich (BAK) method of lumbar interbody fusion. Spine. 1999;24:1857.

23. Branch CL, Branch CL Jr. Posterior lumbar interbody fusion with the keystone graft: technique and results. Surg Neurol. 1987;27:449-54.

24. Hutter CG. Spinal stenosis and posterior lumbar interbody fusion. Clin Orthop Relat Res. 1985;193:103-14.

25. Simmons JW. Posterior lumbar interbody fusion with posterior elements as chip grafts. Clin Orthop Relat Res. 1985;193:85-9.

26. Wiltberger BR. Intervertebral body fusion by the use of posterior bone dowel. Clin Orthop Relat Res. 1964;35:69-79.

27. Brodke DS, Dick JC, Kunz DN, et al. Posterior lumbar interbody fusion. A biomechanical comparison, including a new threaded cage. Spine. 1997;22:26-31.

28. Barnes B, Rodts GE Jr, Haid RW Jr, et al. Allograft implants for posterior lumbar interbody fusion: results comparing cylindrical dowels and impacted wedges. Neurosurgery. 2002;51:1191-8 (discussion 8).

29. Freeman BJ, Licina P, Mehdian SH. Posterior lumbar interbody fusion combined with instrumented postero-lateral fusion: 5-year results in 60 patients. Eur Spine J. 2000;9:42-6.

30. Harms J, Rolinger H. A one-stager procedure in operative treatment of spondylolistheses: dorsal traction-reposition and anterior fusion (author's transl). Z Orthop Ihre Grenzgeb. 1982;120: 343-7.

31. Mummaneni PV, Haid RW, Rodts GE. Lumbar interbody fusion: state-of-the-art technical advances. Invited submission from the Joint Section Meeting on Disorders of the Spine and Peripheral Nerves, March 2004. J Neurosurg Spine. 2004;1:24-30.

32. Resnick DK, Choudhri TF, Dailey AT, et al. Guidelines for the performance of fusion procedures for degenerative disease of the lumbar spine. Part 9: fusion in patients with stenosis and spondylolisthesis. J Neurosurg Spine. 2005;2:679-85.
33. Resnick DK, Choudhri TF, Dailey AT, et al. Guidelines for the performance of fusion procedures for degenerative disease of the lumbar spine. Part 10: fusion following decompression in patients with stenosis without spondylolisthesis. J Neurosurg Spine. 2005; 2:686-91.

34. Zdeblick TA. The treatment of degenerative lumbar disorders. A critical review of the literature. Spine. 1995;20:126S-37S.

35. Esses SI, Botsford DJ, Kostuik JP. The role of external spinal skeletal fixation in the assessment of low-back disorders. Spine. 1989;14:594-601.

36. Stokes IA, Frymoyer JW. Segmental motion and instability. Spine. 1987;12:688-91.

37. Wetzel FT, LaRocca SH, Lowery GL, et al. The treatment of lumbar spinal pain syndromes diagnosed by discography. Lumbar arthrodesis. Spine. 1994;19:792-800.

38. Mooney V, Robertson J. The facet syndrome. Clin Orthop Relat Res. 1976;115:149-56.

39. Kuslich SD, Ulstrom CL, Michael CJ. The tissue origin of low back pain and sciatica: a report of pain response to tissue stimulation during operations on the lumbar spine using local anesthesia. Orthop Clin North Am. 1991;22:181-7.

40. McCarron RF, Wimpee MW, Hudkins PG, et al. The inflammatory effect of nucleus pulposus. A possible element in the pathogenesis of low-back pain. Spine. 1987;12:760-4.

41. Olmarker K, Rydevik B, Nordborg C. Autologous nucleus pulposus induces neurophysiologic and histologic changes in porcine cauda equina nerve roots. Spine. 1993;18:1425-32.

42. Greenough CG, Fraser RD. The effects of compensation on recovery from low-back injury. Spine. 1989;14:947-55.

43. Deyo RA, Cherkin D, Conrad D, et al. Cost, controversy, crisis: low back pain and the health of the public. Annu Rev Public Health. 1991;12:141-56.

44. Frymoyer JW, Pope MH, Clements JH, et al. Risk factors in lowback pain. An epidemiological survey. J Bone Joint Surg Am. 1983;65:213-8.

45. Khoo LT, Palmer S, Laich DT, et al. Minimally invasive percutaneous posterior lumbar interbody fusion. Neurosurgery. 2002;51:S166-81.

46. Rosenberg WS, Mummaneni PV. Transforaminal lumbar interbody fusion: technique, complications, and early results. Neurosurgery. 2001;48:569-74 (discussion 74-5).

47. Grob D, Scheier HJ, Dvorak J, et al. Circumferential fusion of the lumbar and lumbosacral spine. Arch Orthop Trauma Surg. 1991;111:20-5.

48. Kim SS, Denis F, Lonstein JE, et al. Factors affecting fusion rate in adult spondylolisthesis. Spine. 1990;15:979-84.

49. Kozak JA, O’Brien JP. Simultaneous combined anterior and posterior fusion. An independent analysis of a treatment for the disabled low-back pain patient. Spine. 1990;15:322-8.

50. Slosar PJ, Reynolds JB, Schofferman J, et al. Patient satisfaction after circumferential lumbar fusion. Spine. 2000;25:722-6.

51. Enker P, Steffee AD. Interbody fusion and instrumentation. Clin Orthop Relat Res. 1994;300:90-101.

52. Gertzbein SD, Hollopeter MR, Hall S. Pseudarthrosis of the lumbar spine. Outcome after circumferential fusion. Spine. 1998;23:2352-6 (discussion 6-7).

53. Ames CP, Acosta FL Jr, Chi J, et al. Biomechanical comparison of posterior lumbar interbody fusion and transforaminal lumbar interbody fusion performed at 1 and 2 levels. Spine. 2005; 30:E562-6.

54. Salehi SA, Tawk R, Ganju A, et al. Transforaminal lumbar interbody fusion: surgical technique and results in 24 patients. Neurosurgery. 2004;54:368-74 (discussion 74).

55. Blume HG. Unilateral posterior lumbar interbody fusion: simplified dowel technique. Clin Orthop Relat Res. 1985;193:75-84. 
56. Evans JH. Biomechanics of lumbar fusion. Clin Orthop Relat Res. 1985;193:38-46.

57. Branch CL Jr. The case for posterior lumbar interbody fusion. Clin Neurosurg. 1996;43:252-67.

58. Krishna M, Pollock RD, Bhatia C. Incidence, etiology, classification, and management of neuralgia after posterior lumbar interbody fusion surgery in 226 patients. Spine J. 2008;8:374-9.

59. Sears W. Posterior lumbar interbody fusion for degenerative spondylolisthesis: restoration of sagittal balance using insert-androtate interbody spacers. Spine J. 2005;5:170-9.

60. Gerber M, Crawford NR, Chamberlain RH, et al. Biomechanical assessment of anterior lumbar interbody fusion with an anterior lumbosacral fixation screw-plate: comparison to stand-alone anterior lumbar interbody fusion and anterior lumbar interbody fusion with pedicle screws in an unstable human cadaver model. Spine. 2006;31:762-8.

61. Maghout Juratli S, Franklin GM, Mirza SK, et al. Lumbar fusion outcomes in Washington State workers' compensation. Spine. 2006;31:2715-23.

62. Weiner BK, Fraser RD. Spine update lumbar interbody cages. Spine. 1998;23:634-40.

63. Wang ST, Goel VK, Fu CY, et al. Comparison of two interbody fusion cages for posterior lumbar interbody fusion in a cadaveric model. Int Orthop. 2006;30:299-304.

64. Brantigan JW, Steffee AD. A carbon fiber implant to aid interbody lumbar fusion. Two-year clinical results in the first 26 patients. Spine. 1993;18:2106-7.

65. Vadapalli S, Sairyo K, Goel VK, et al. Biomechanical rationale for using polyetheretherketone (PEEK) spacers for lumbar interbody fusion-A finite element study. Spine. 2006;31:E992-8.

66. Jost B, Cripton PA, Lund $\mathrm{T}$, et al. Compressive strength of interbody cages in the lumbar spine: the effect of cage shape, posterior instrumentation and bone density. Eur Spine J. 1998;7:132-41.

67. Humphreys SC, Hodges SD, Patwardhan AG, et al. Comparison of posterior and transforaminal approaches to lumbar interbody fusion. Spine. 2001;26:567-71.

68. Lowe TG, Coe JD. Resorbable polymer implants in unilateral transforaminal lumbar interbody fusion. J Neurosurg. 2002; 97:464-7.
69. Gibson S, McLeod I, Wardlaw D, et al. Allograft versus autograft in instrumented posterolateral lumbar spinal fusion: a randomized control trial. Spine. 2002;27:1599-603.

70. Mummaneni PV, Pan J, Haid RW, et al. Contribution of recombinant human bone morphogenetic protein-2 to the rapid creation of interbody fusion when used in transforaminal lumbar interbody fusion: a preliminary report. Invited submission from the Joint Section Meeting on Disorders of the Spine and Peripheral Nerves, March 2004. J Neurosurg Spine. 2004;1:19-23.

71. Alexander JT, Branch CL Jr, Subach BR, et al. Applications of a resorbable interbody spacer in posterior lumbar interbody fusion. J Neurosurg. 2002;97:468-72.

72. Resnick DK, Choudhri TF, Dailey AT, et al. Guidelines for the performance of fusion procedures for degenerative disease of the lumbar spine. Part 16: bone graft extenders and substitutes. J Neurosurg Spine. 2005;2:733-6.

73. Burkus JK, Heim SE, Gornet MF, et al. Is INFUSE bone graft superior to autograft bone? An integrated analysis of clinical trials using the LT-CAGE lumbar tapered fusion device. J Spinal Disord Tech. 2003;16:113-22.

74. Boden SD, Kang J, Sandhu H, et al. Use of recombinant human bone morphogenetic protein-2 to achieve posterolateral lumbar spine fusion in humans: a prospective, randomized clinical pilot trial: 2002 Volvo Award in clinical studies. Spine. 2002;27:266273.

75. Kasai Y, Takegami K, Uchida A. Mixture ratios of local bone to artificial bone in lumbar posterolateral fusion. J Spinal Disord Tech. 2003;16:31-7.

76. Linovitz RJ, Peppers TA. Use of an advanced formulation of beta-tricalcium phosphate as a bone extender in interbody lumbar fusion. Orthopedics. 2002;25:s585-9.

77. Thalgott JS, Giuffre JM, Fritts K, et al. Instrumented posterolateral lumbar fusion using coralline hydroxyapatite with or without demineralized bone matrix, as an adjunct to autologous bone. Spine J. 2001;1:131-7. 